DOI: $10.1355 / a e 23-3 a$

\title{
Poverty and Growth in Southeast Asia
}

\author{
Peter Warr
}

\begin{abstract}
Over recent decades, most countries of Southeast Asia achieved reductions in absolute poverty incidence, but these reductions varied in magnitude between countries and over time. This paper shows that differences in the rate and sectoral composition of economic growth explain part, but not all, of these differences. It describes outcomes on poverty incidence in Southeast Asia and relates them to the growth of output in the agricultural, industrial, and services sectors. This analysis uses data from the 1970s to the most recent available for Indonesia, Thailand, Malaysia, and the Philippines to analyse the economic determinants of changes in poverty incidence in Southeast Asia.
\end{abstract}

Keywords: Poverty incidence, Southeast Asia, inequality.

\section{Introduction}

Throughout most of Southeast Asia, measured poverty incidence has declined dramatically in the last three decades. In some cases, these reductions in absolute poverty incidence have occurred in spite of increasing inequality. At the same time, long-term economic growth has been impressive throughout most of the region, despite temporary setbacks like the financial crisis of 1997-98. To what extent can the achievement of poverty reduction be explained by the economic growth that coincided with it? Does the fact that growth coincided with poverty reduction show that the former caused the latter? And even if it did, is growth all that matters for poverty alleviation?

The question is important. If economic growth explained all of the poverty reduction, then the path to eliminating poverty would simply be to maximize the sustainable rate of growth. If it explained none of it, then those interested in poverty reduction could safely ignore the determinants of economic growth, focusing exclusively on other strategies such as identifying and assisting poor people at a local level. Although both of these polar positions have their adherents, it seems highly unlikely that either extreme could be correct. But where, in between them, does the truth lie?

The presumption that economic growth will reduce poverty is uncontroversial among economists. Non-economists tend to be more sceptical.' The economist's expectation that growth reduces absolute poverty in the long term is based on the statistical definition of absolute 
poverty incidence and two empirical observations. Absolute poverty incidence is defined as the proportion of the population whose incomes or expenditures fall below a given threshold, the "poverty line", a level of income or expenditure whose nominal value is adjusted over time to hold its real purchasing power constant. The level of real income represented by this threshold is essentially arbitrary, but once it is determined, poverty incidence depends simply on the size of the economic pie and its distribution.

The two empirical observations are: (i) whereas the size of the pie (real national income per person) can change considerably over time, the degree of inequality generally changes only slowly; and (ii) the changes in inequality that do occur are not systematically related to the rate of growth. Changes in poverty incidence must therefore normally be statistically related to changes in the size of the pie - via economic growth or its reversal. Exceptions are possible, but they should be rare.

According to this view, in the long term, economic growth is a necessary condition for large-scale poverty reduction, because no amount of redistribution could turn a poor country into a rich one. It will also be a sufficient condition, even in the short term, provided inequality does not increase "too much".

The available empirical evidence supports this expectation: on average, the faster the growth, the greater the reduction in absolute poverty. Nevertheless, while differences in aggregate rates of growth explain much of the observed differences in rates of poverty reduction, they do not explain all of it. It is obvious that poverty incidence could be affected by factors other than just the rate of growth. These factors may include distributive policies targeted towards (or away from) poor people, technological change, movements in commodity prices due to fluctuating production conditions and changes in the international economic environment. The relative importance of these factors and the efficacy of policy interventions directed to reducing poverty are important matters for quantitative research.

But the emphasis on the aggregate rate of growth may be overly simplistic for another reason. The nature of the growth may also be important - itself influenced by the policy environment in place. The literature on economic development has emphasized the sectoral composition of growth as a possible determinant of its distributional effects, although this emphasis has usually been based primarily on a priori theorizing, rather than empirical analysis. In most poor countries a majority of the poor live in rural areas and are employed in agriculture. From this it has seemed probable that growth of agriculture is more important for poverty reduction than growth of industry or services. Many authors in the development economics field have taken this view, but the conclusion does not necessarily follow.

People are potentially mobile. Given sufficient time, even poor people can presumably move to whichever sector is generating the growth and thereby generating incomes. Rural poverty may therefore be reduced by urban-based growth, drawing at least some of the poor away from rural areas (Chenery and Syrquin 1986; Fields 1980). When intersectoral factor mobility is taken into account, it is not obvious that the sectoral composition of growth is important for poverty reduction. Of course, labour may not be fully mobile, even in the long run. Moreover, even if poor people were fully and instantaneously mobile, poverty incidence could still be affected by the sectoral composition of growth.

To a first order of approximation, the level of absolute poverty incidence depends on the incomes of the poor, which presumably depends on the demand for the factors of production that they own, especially unskilled labour and, to a lesser extent, agricultural land. Growth in different sectors has differential effects on the demands for these factors, depending on these sectors' factor intensities, and may therefore have different effects on poverty. Finally, it is important that the distinction rural-urban is not synonymous with the distinction agriculture-non-agriculture. Much agricultural production may occur in full or parttime farming on the fringes of urban areas and much industrial and services activity may actually occur in rural areas. 


\section{Measuring Poverty}

Before we can analyse the causes of poverty or the determinants of changes in it, we must first quantify it. The measurement issues involved in estimating poverty incidence are complex and compromises abound in empirical applications. Empirical measurement of poverty lags well behind thinking about its broader meaning. Official poverty measures should be seen as a component, but not the only component, of efforts to monitor poverty incidence. A broadening of the methods used to measure poverty incidence would be both possible and desirable. Before turning to the more technical aspects of poverty measurement, four observations regarding the broader dimensions of poverty measurement will be discussed.

First, although poverty is of course more than just a low level of income or expenditure, the various dimensions of poverty do tend to be highly correlated. People who are poor by one measure tend, generally speaking, to be poor by another. This means that accuracy in measuring poverty by narrow measures like real incomes or real expenditures, may be useful even though it does not capture all of the elements of poverty that may reasonably be considered relevant.

Second, it is important for users of poverty measures to be able to compare poverty incidence over time. This means that changes to the measurement of poverty should take the form of adding to the set of measures already in place, rather than replacing them. When existing measures are discontinued, the comparability of poverty measures over time is lost.

Third, objective quantification is important. As far as possible, poverty measures need to avoid personal opinion affecting the measures, because such opinions differ among individuals and can change over time. Subjectivity can enter at the level of primary data collection or at the level of analysis. To some extent, this is inevitable but it needs to be minimized. If poverty measures involved large elements of subjectivity on the part of enumerators, say, users of the data would be unable to distinguish between, on the one hand, changes over time in the true situation of poor people and, on the other, changes over time in the personal views of the enumerators, who may not even be the same individuals. The same applies to comparisons across regions, where the enumerators will necessarily be different individuals.

Fourth, poverty estimates are controversial and can have political consequences. The statistical organizations are responsible for compiling the household survey data on which poverty estimates are based and the subsequent analysis of those data are generally done by government agencies. In some countries the politicization of poverty measures has caused the informed public to lose confidence in the integrity of the government statistical agencies responsible for producing the poverty estimates. Even if this does not occur, poverty estimation involves many technical and conceptual issues which are open to debate and honest disagreement. It is important that such a debate occur within an atmosphere of transparency and people have open access to the information on which the estimates are based. Poverty estimates need to be verifiable by qualified external observers and where they consider it necessary, those analysts must be free to apply alternative methodologies to the raw data. The continued openness of this process is the means by which public confidence in the reliability of the estimates can be maintained.

Six kinds of issues are involved in quantitative measurement of poverty incidence over time.

1. Are we discussing absolute or relative poverty? Measures of absolute poverty relate to that part of the population whose incomes (or expenditures) fall below a given level (the poverty line) whose value is held fixed in real purchasing power over time and across social groups. Relative poverty means inequality, and to avoid confusion it is probably better to use that term. It compares the incomes (or expenditures) of the poor with those of the rich, or some other reference group. The two concepts are different because the overall size of the economic pie may change at the same time as its distribution is changing. Not surprisingly, when the overall size of the economic pie is 
changing significantly, measures of absolute poverty and inequality do not necessarily move together and may not even change in the same direction.

2. What variable is used for the calculations of poverty incidence? In Thailand, Malaysia, and the Philippines the basis used in all available studies has been household incomes per household member, adjusted for gender and age distribution of the household. In most other countries (Indonesia, Vietnam, Cambodia, and Lao PDR, for example), household expenditures are used. The use of household expenditures for measurement of poverty is more consistent with economic theory, in that expenditures are more directly related to household welfare than incomes, but this issue has been ignored in most of the literature dealing with poverty measurement in Thailand. The distinction between income-based and expenditure-based measures of poverty is especially important when we are considering the impact on poverty of a short-term reduction (or increase) in incomes. The recent Asian financial crisis provides a good example.

3. What is the poverty measure? Most studies of poverty focus on the headcount measure of absolute poverty incidence, which means the proportion of the population whose incomes fall below a given threshold, held constant in real terms over time and across regions. At a conceptual level, this measure has the disadvantage that changes in it are due mainly to changes in the living conditions of members of the population with incomes or expenditures close to the poverty line. Other measures of absolute poverty incidence lacking this disadvantage have been calculated from time to time, such as the poverty gap and poverty gap squared measures, but are normally highly correlated with the headcount measure. Concentration on the headcount measure therefore seems warranted.

4. What data source is used for the calculations? Household level survey data are essential, but the statistical design and frequency of these surveys varies between countries. For example, in Thailand the periodic Socio-Economic Surveys (SES) conducted by the Thai government's National Statistical Office (NSO) provide virtually the sole source of reliable information at the household level that can be compared over time (Krongkaew 1993 and Warr 2005). This survey was conducted at irregular intervals prior to the 1980s. The earliest round of the survey for which poverty incidence can confidently be compared with later periods relates to $1975 / 76$. Another was undertaken in 1981 and, since 1986, surveys have been conducted every two years. ${ }^{2}$ In Indonesia, the SUSENAS survey plays a similar role. It is conducted annually, but the specialized "consumption module", which provides the most reliable basis for poverty estimation based on expenditures, is conducted only every three years (see tables below).

5. How is the base level of the poverty line determined? Some concept of the minimum level of income or expenditure per person must be established for a household to be classified as nonpoor. Although studies of poverty measurement often give great attention to this matter, drawing upon studies of minimum nutritional requirements, but the level of this poverty line necessarily involves a large element of arbitrariness.

6. What is the poverty line deflator? This involves the way the poverty line is adjusted over time to keep its real purchasing power constant. Although this may seem a minor technical matter, it is a central issue for poverty measurement over time and across regions where consumer prices vary. Empirical studies of poverty incidence differ in their handling of this issue. The ideal deflator uses the actual expenditure pattern of the poor to weigh price changes at the commodity level. This deflator may, at times, behave differently from the overall consumer price index, which reflects "average" expenditure patterns. But many studies use arbitrary baskets of goods and services in constructing the poverty line deflator. A common mistake is to confuse the determination of the base level of poverty line, whose composition may 
differ considerably from the bundles actually consumed by the poor, with the determination of the appropriate cost of living deflator.

\section{Poverty Incidence in Southeast Asia}

Available data on poverty incidence and inequality in seven ASEAN countries are summarized in Tables 1 to 7 and in Figures 1 to 7. The exception is Myanmar (Burma), for which data are unavailable. For Indonesia, Thailand, Malaysia, and the Philippines, the data are based on official statistics reporting the headcount measure of absolute poverty incidence published by the national statistical agencies, converted to a constant real value of the poverty line. These data were unavailable for Cambodia, Lao PDR, and Vietnam, and World Bank data for these countries are reported instead.

Two important sources of difference between the poverty estimates for these seven countries should be noted. First, the poverty incidence data for Thailand, Malaysia, and the Philippines are based on comparisons of household incomes with an official poverty line adjusted over time to hold real purchasing power constant. However, the data for Indonesia, Cambodia, Lao PDR, and Vietnam are based on comparison of household expenditures with such a poverty line. This difference could introduce some inconsistencies between Indonesia and the other three countries in the short-run behaviour of the resulting poverty estimates. During periods when incomes rise unexpectedly, incomes should rise faster than expenditures and poverty incidence estimates based on incomes should decline faster. When incomes fall unexpectedly (the Asian financial crisis of 1997-98, for example) the reverse should occur; poverty estimates based on incomes should rise faster than estimates based on expenditures. Nevertheless, this difference is not necessarily important for the long-term relationships between poverty incidence and sectoral growth that are studied in this paper.

TABLE 1

Indonesia: Poverty Incidence and Inequality, 1976-2002

(Units: per cent, except Gini coefficient)

\begin{tabular}{lcccc}
\hline & $\begin{array}{c}\text { National Poverty } \\
(P)\end{array}$ & $\begin{array}{c}\text { Rural Poverty } \\
\left(P^{R}\right)\end{array}$ & $\begin{array}{c}\text { Urban Poverty } \\
\left(P^{U}\right)\end{array}$ & $\begin{array}{c}\text { Gini } \\
\text { Coefficient }\end{array}$ \\
\hline 1976 & 63.3 & 65.4 & 54.4 & 0.34 \\
1978 & 53.6 & 54.0 & 43.2 & 0.38 \\
1980 & 44.2 & 45.9 & 40.7 & 0.34 \\
1984 & 33.9 & 34.3 & 32.4 & 0.33 \\
1987 & 26.7 & 26.0 & 28.2 & 0.32 \\
1990 & 23.3 & 23.1 & 23.6 & 0.32 \\
1993 & 21.4 & 22.3 & 18.8 & 0.34 \\
1996 & 17.7 & 19.9 & 13.6 & 0.36 \\
1999 & 23.4 & 26.0 & 19.4 & 0.31 \\
2002 & 18.2 & 21.1 & 14.5 & 0.33 \\
\hline
\end{tabular}

NoTEs: National poverty is the percentage of the total population whose incomes fall below a poverty line held constant over time in real terms; rural poverty is the percentage of the rural population whose incomes fall below a poverty line held constant over time in real terms, and so forth.

SourCES: Poverty estimates from Statistical Yearbook of Indonesia, various issues, Central Bureau of Statistics, Jakarta, based on household expenditure data collected in the SUSENAS survey; inequality estimates from Islam (2004). 
TABLE 2

Thailand: Poverty Incidence and Inequality, 1969-2002

(Units: per cent, except Gini coefficient)

\begin{tabular}{ccccc}
\hline & $\begin{array}{c}\text { National Poverty } \\
(P)\end{array}$ & $\begin{array}{c}\text { Rural Poverty } \\
\left(P^{R}\right)\end{array}$ & $\begin{array}{c}\text { Urban Poverty } \\
\left(P^{U}\right)\end{array}$ & $\begin{array}{c}\text { Gini } \\
\text { Coefficient }\end{array}$ \\
\hline 1969 & 63.1 & 69.6 & 53.7 & 0.43 \\
1975 & 48.6 & 57.2 & 25.8 & 0.43 \\
1981 & 35.5 & 43.1 & 15.5 & 0.43 \\
1986 & 44.9 & 56.3 & 12.1 & 0.48 \\
1988 & 32.6 & 40.3 & 12.6 & 0.48 \\
1990 & 27.2 & 33.8 & 1.6 & 0.52 \\
1992 & 23.2 & 29.7 & 6.6 & 0.54 \\
1994 & 16.3 & 21.2 & 4.8 & 0.52 \\
1996 & 11.4 & 14.9 & 3.0 & 0.52 \\
1998 & 12.9 & 17.2 & 3.4 & 0.52 \\
1999 & 15.9 & 21.5 & 3.1 & 0.52 \\
2000 & 14.2 & 19.1 & 3.6 & 0.53 \\
2001 & 13.0 & 16.6 & 5.1 & 0.52 \\
2002 & 9.8 & 12.6 & 3.8 & 0.51 \\
\hline
\end{tabular}

Source: National Economic and Social Development Board, Bangkok, based on household income data collected in the Socio-Economic Survey.

TABLE 3

Malaysia: Poverty Incidence and Inequality, 1970-99

(Units: per cent, except Gini coefficient)

\begin{tabular}{ccccc}
\hline & $\begin{array}{c}\text { National Poverty } \\
(P)\end{array}$ & $\begin{array}{c}\text { Rural Poverty } \\
\left(P^{R}\right)\end{array}$ & $\begin{array}{c}\text { Urban Poverty } \\
\left(P^{U}\right)\end{array}$ & $\begin{array}{c}\text { Gini } \\
\text { Coefficient }\end{array}$ \\
\hline 1970 & 52.4 & n.a. & n.a. & 0.51 \\
1976 & 42.4 & 50.9 & 18.7 & 0.53 \\
1984 & 20.7 & 27.3 & 8.5 & 0.48 \\
1990 & 17.1 & 21.8 & 7.5 & 0.45 \\
1993 & 13.4 & 18.6 & 5.3 & 0.46 \\
1995 & 8.7 & 14.9 & 3.6 & 0.46 \\
1997 & 6.1 & 10.9 & 2.1 & 0.47 \\
1999 & 7.5 & 12.4 & 3.4 & 0.44 \\
2002 & 5.1 & 11.4 & 2.0 & 0.46 \\
\hline
\end{tabular}

SourCE: Tables 2 and 6 in Rogayah (2004). 
TABLE 4

Philippines: Poverty Incidence and Inequality, 1961-2003

(Units: per cent, except Gini coefficient)

\begin{tabular}{lcccc}
\hline & $\begin{array}{c}\text { National Poverty } \\
(P)\end{array}$ & $\begin{array}{c}\text { Rural Poverty } \\
\left(P^{R}\right)\end{array}$ & $\begin{array}{c}\text { Urban Poverty } \\
\left(P^{U}\right)\end{array}$ & $\begin{array}{c}\text { Gini } \\
\text { Coefficient }\end{array}$ \\
\hline 1961 & 51.4 & 67.3 & 27.6 & 0.50 \\
1965 & 46.0 & 59.7 & 24.3 & 0.51 \\
1971 & 42.3 & 55.4 & 21.8 & 0.49 \\
1985 & 40.9 & 53.1 & 21.7 & 0.46 \\
1988 & 34.4 & 45.7 & 16.0 & 0.46 \\
1991 & 34.3 & 48.6 & 20.1 & 0.47 \\
1994 & 32.1 & 45.4 & 18.6 & 0.46 \\
1997 & 25.0 & 36.9 & 11.9 & 0.47 \\
2000 & 27.5 & 41.3 & 13.2 & 0.46 \\
2003 & 24.7 & 38.5 & 12.0 & 0.47 \\
\hline
\end{tabular}

SOURCES:

1. 1961-71, from National Statistical Office, Manila, based on household income data collected in the Family Income and Expenditure Survey.

2. $1985-2000$ from Balisacan (2002).

3. 2003 from website of Philippines National Statistical Coordination Bureau, http://www.nscb. gov.ph.

TABLE 5

Cambodia: Poverty Incidence and Inequality, 1996-2001

(Units: per cent, except Gini coefficient)

\begin{tabular}{ccc}
\hline & National Poverty $(P)$ & Gini Coefficient \\
\hline 1996 & 36.7 & 0.42 \\
1997 & 38.4 & 0.42 \\
1998 & 37.7 & 0.42 \\
1999 & 37.7 & 0.42 \\
2000 & 35.6 & 0.41 \\
2001 & 33.5 & 0.42 \\
\hline
\end{tabular}

SouRCE: World Bank (2002), Appendix Table 8.
TABLE 6

Vietnam: Poverty Incidence and Inequality, 1996-2001

(Units: per cent, except Gini coefficient)

\begin{tabular}{ccc}
\hline & National Poverty $(P)$ & Gini Coefficient \\
\hline 1996 & 25.4 & 0.36 \\
1998 & 15.0 & 0.35 \\
1999 & 12.6 & 0.35 \\
2000 & 9.6 & 0.35 \\
2001 & 8.9 & 0.36 \\
\hline
\end{tabular}

Source: World Bank (2002), Appendix Table 8. 
TABLE 7

Lao PDR: Poverty Incidence and Inequality, 1992-2002

(Units: per cent, except Gini coefficient)

\begin{tabular}{ccccc}
\hline & $\begin{array}{c}\text { National Poverty } \\
(P)\end{array}$ & $\begin{array}{c}\text { Rural Poverty } \\
\left(P^{R}\right)\end{array}$ & $\begin{array}{c}\text { Urban Poverty } \\
\left(P^{U}\right)\end{array}$ & $\begin{array}{c}\text { Gini } \\
\text { Coefficient }\end{array}$ \\
\hline 1992 & 46.0 & 51.8 & 26.5 & 0.31 \\
1997 & 39.1 & 42.5 & 22.1 & 0.35 \\
2002 & 30.7 & 33.0 & 23.0 & 0.33 \\
\hline
\end{tabular}

SouRCE: Kaspar Richter, “Some Poverty Statistics of Lao PDR”, World Bank, Vientiane, March 2004.

FIGURE 1

Indonesia: Poverty Incidence and Inequality, 1976-2002

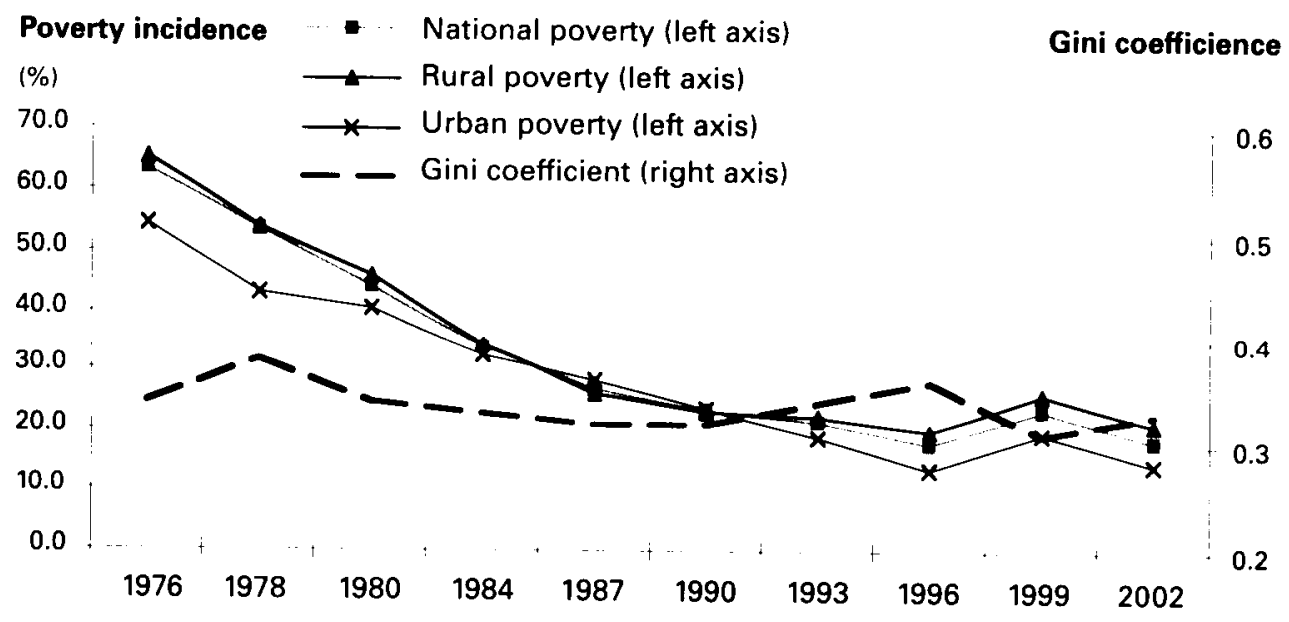

SourcE: See Table 1.

Second, the real purchasing powers of the poverty lines used in each of the seven countries are different. Even if the distributions of real incomes (expenditures) in the four countries were exactly the same, which they are not, this would mean that the poverty lines would relate to different points on these distributions.

Over the periods shown in Tables 1 to 7 , the longest for which useable data are available, national poverty incidence declined substantially in each of these seven countries. In each case, this decline occurred in both rural and urban areas. But inequality, as measured by the Gini coefficient, behaved quite differently. In Thailand it increased, in Malaysia and the Philippines it declined, and in the four other cases - Indonesia, Cambodia, Lao PDR, and Vietnam - it remained virtually constant. 
FIGURE 2

Thailand: Poverty Incidence and Inequality, 1969-2002

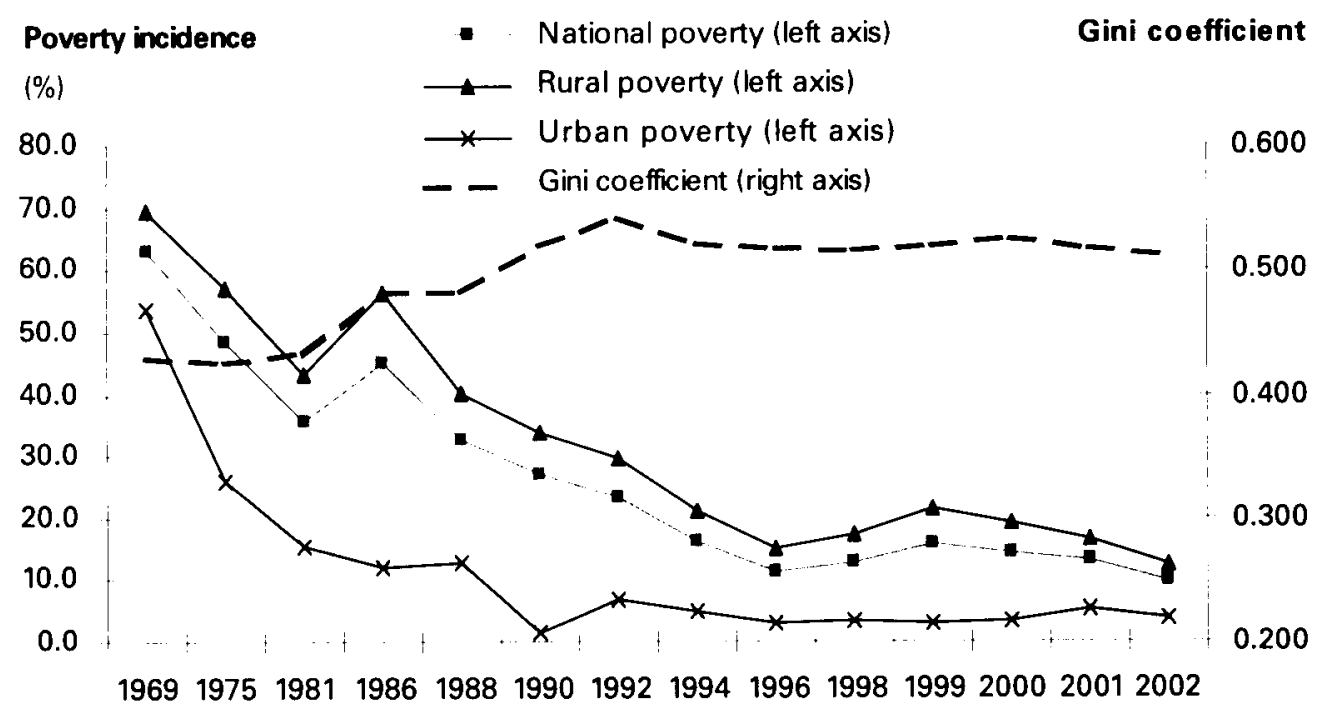

SourcE: See Table 2.

FIGURE 3

Malaysia: Poverty Incidence and Inequality, 1970-2002

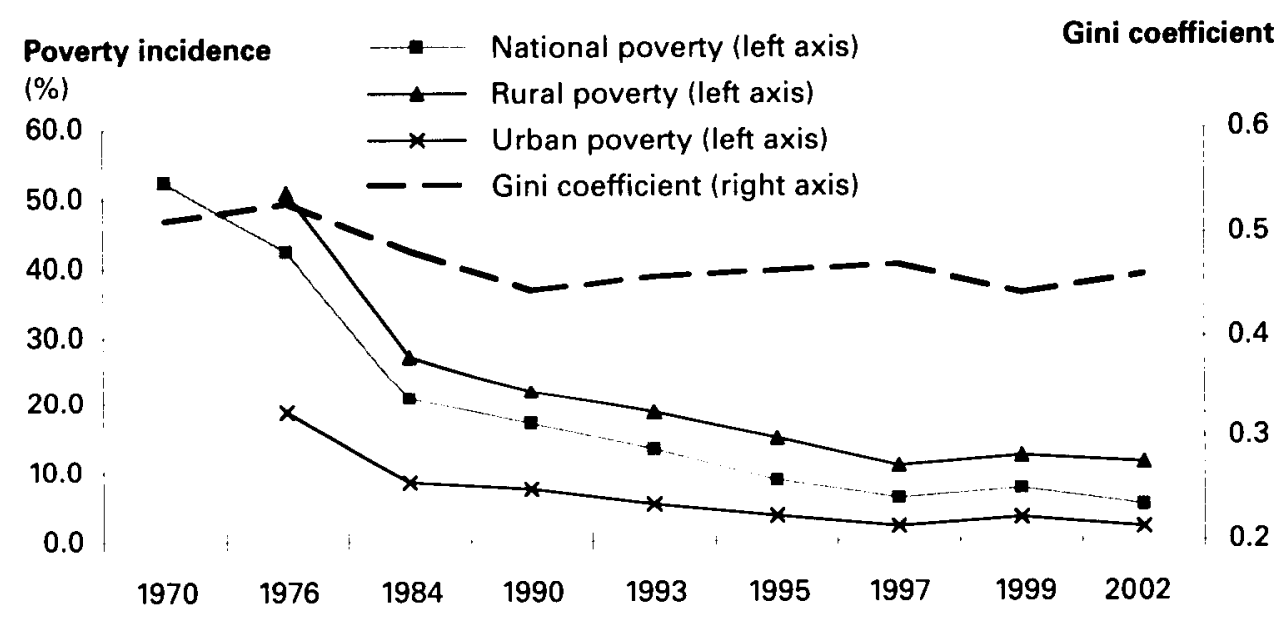

SOURCE: See Table 3. 
FIGURE 4

Philippines: Poverty Incidence and Inequality, 1961-2003

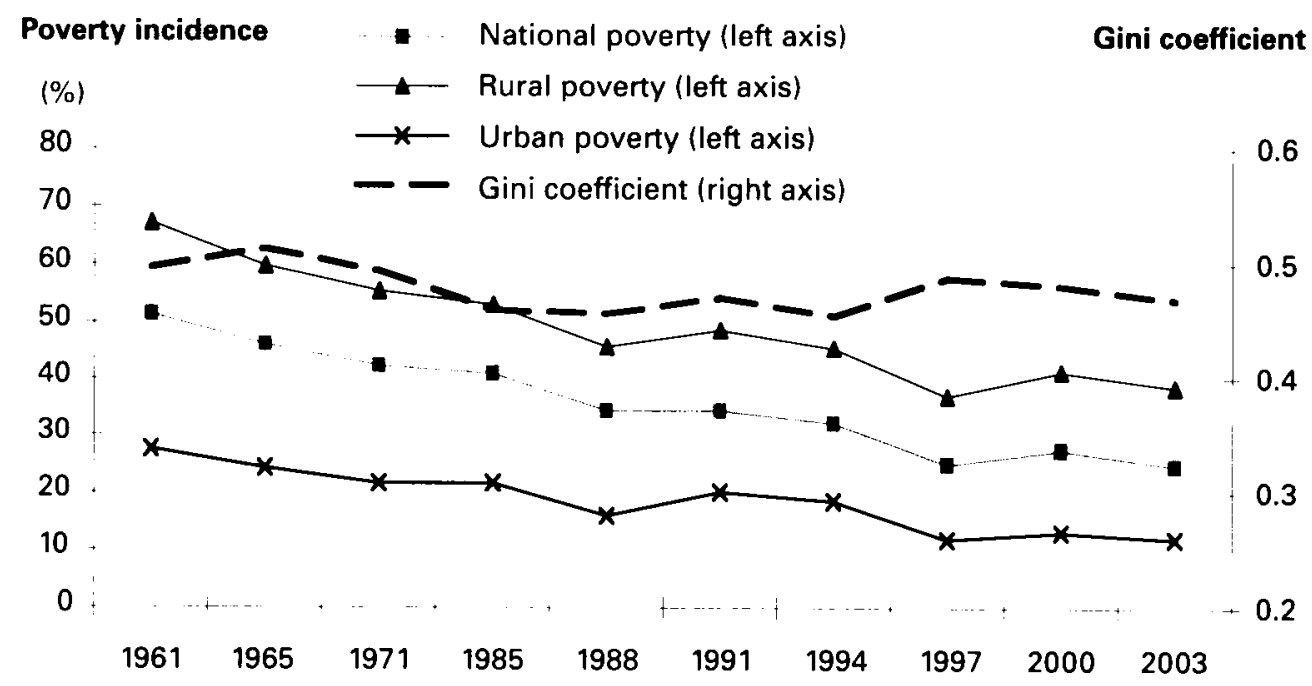

SourCE: See Table 4.

FIGURE 5

Cambodia: Poverty Incidence and Inequality, 1996-2001

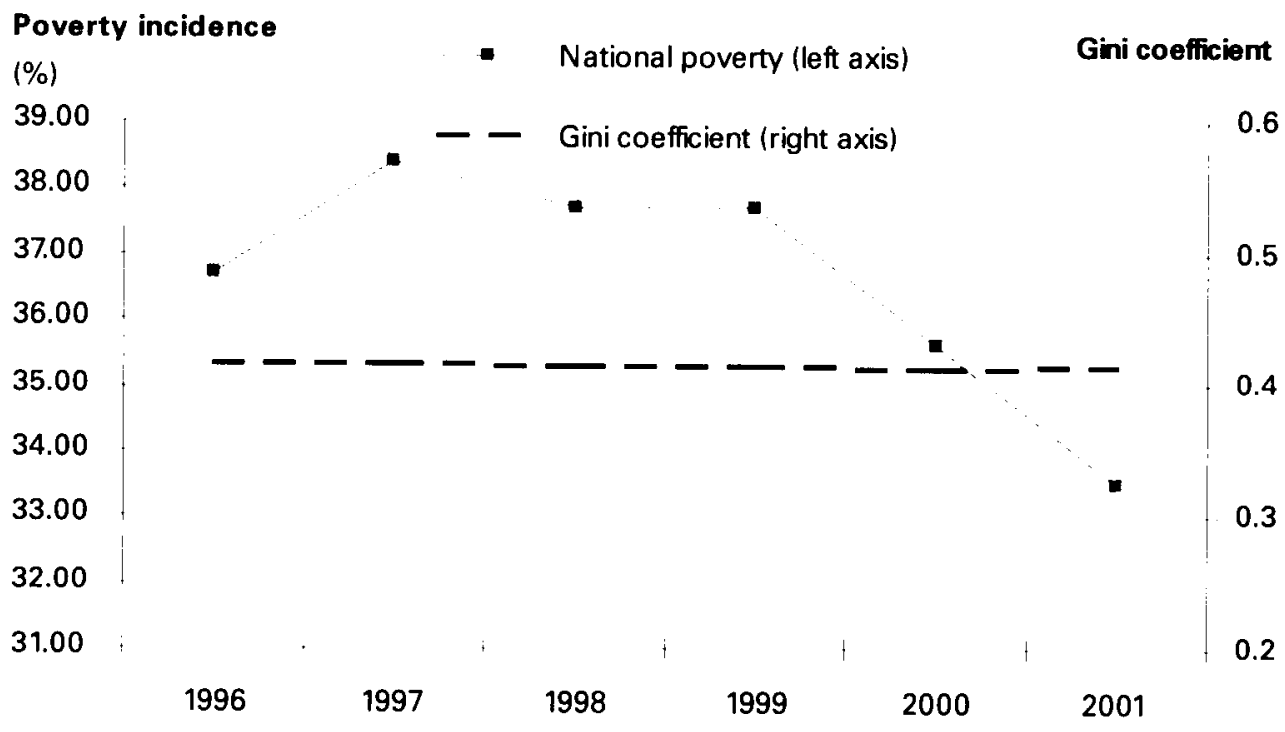

SoURCE: See Table 5. 


\section{FIGURE 6}

Vietnam: Poverty Incidence and Inequality, 1996-2001

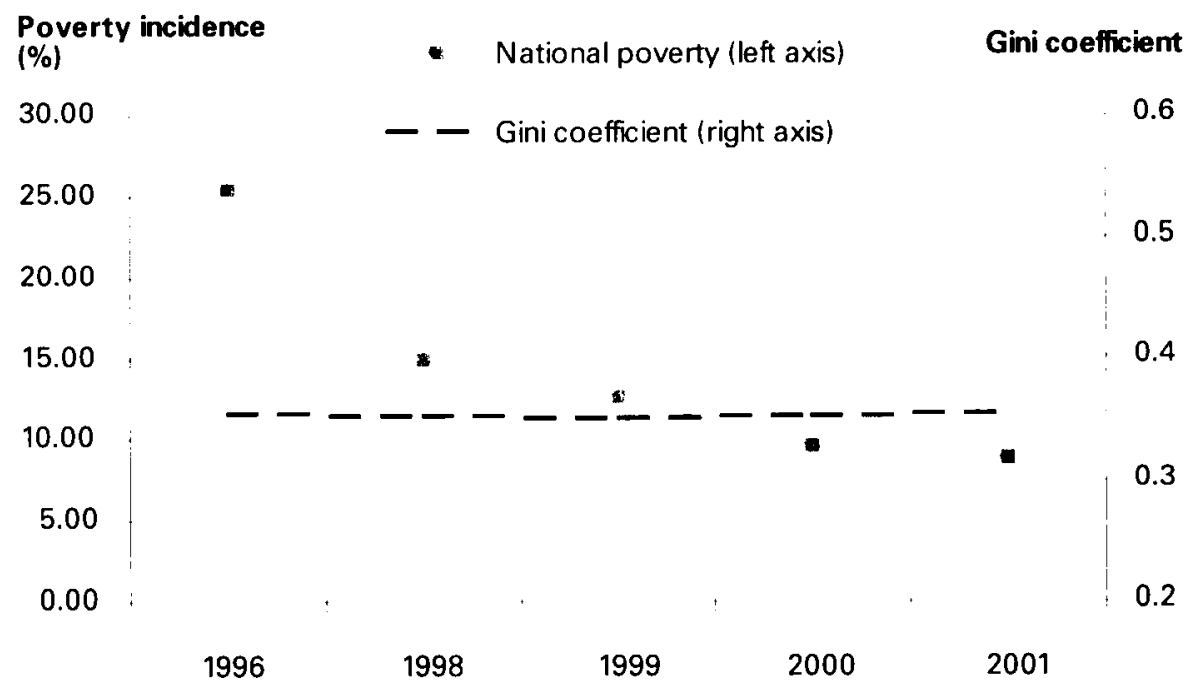

SourcE: See Table 6.

FIGURE 7

Lao PDR: Poverty Incidence and Inequality, 1992-2002

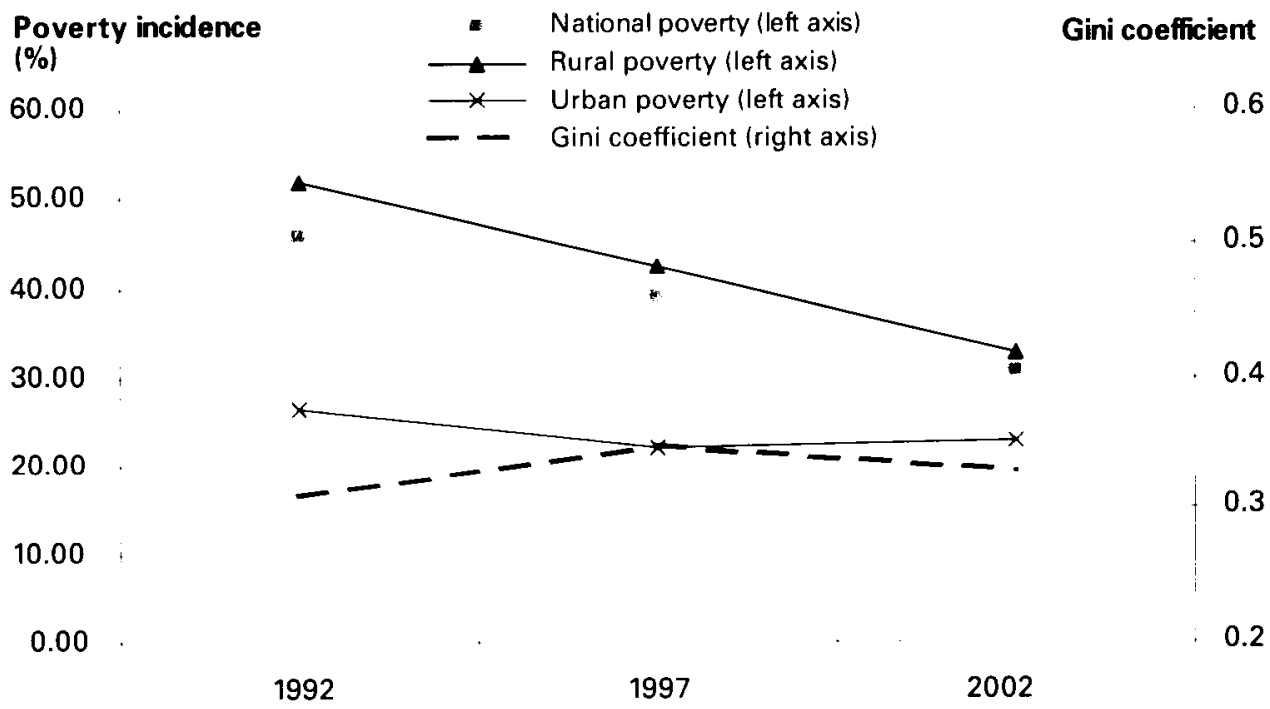

SourcE: See Table 7. 
The subsequent analysis focuses on just four of these countries - Indonesia, Thailand, Malaysia, and the Philippines. These are the four for which national poverty incidence data are available and for which these data are available over a period longer than a decade. The data for these four countries are summarized in Table 8, which shows the mean values of the annual rates of change of national, rural and urban poverty incidence and also the contribution of rural to urban migration. The relationships between these aggregates may be understood as follows.

We shall write $N, N^{R}$ and $N^{U}$ for the national, rural and urban populations, respectively, where $N=N^{R}+N^{U}$. We write $\alpha^{R}=N^{R} / N$ and $\alpha^{U}=N^{U} / N$ for the rural and urban shares of the national population, respectively, where $\alpha^{R}+\alpha^{U}=1$. The total number of people in poverty is given by $N_{P}=N_{P}^{R}+N_{P}^{U}$, where $N_{P}^{R}$ and $N_{P}^{U}$ denote the number in poverty in rural and urban areas, respectively. National poverty incidence is given by

$$
P=N_{P} / N=\left(N_{P}^{R}+N_{P}^{U}\right) / N=\alpha^{R} P^{R}+\alpha^{U} P^{U},
$$

where $P^{R}=N_{P}^{R} / N^{R}$ denotes the proportion of the rural population that is in poverty and $P^{U}=N_{P}^{U} / N^{U}$ the corresponding incidence of poverty in urban areas. Now, differentiating (1), we obtain a key relationship,

$$
d P=\alpha^{R} d P^{R}+\alpha^{U} d P^{U}+\left(P^{R}-P^{U}\right) d \alpha^{R} .
$$

TABLE 8

Data Decomposition: Annual Rate of Change of Poverty Incidence

\begin{tabular}{lcccc}
\hline & \multicolumn{4}{c}{ Actual } \\
\cline { 2 - 5 } & Indonesia & Thailand & Malaysia & Philippines \\
\hline National $^{\mathrm{b}}$ & -1.414 & -1.862 & -1.589 & -0.941 \\
Rural $^{\mathrm{c}}$ & -0.582 & -1.043 & -1.094 & -0.484 \\
Urban $^{\mathrm{d}}$ & -0.262 & -0.187 & -0.298 & -0.369 \\
Migration $^{\mathrm{e}}$ & -0.57 & -0.632 & -0.197 & -0.088 \\
& & & & \\
& & Normalized & (national $=100)$ & \\
National $^{\mathrm{b}}$ & 100 & 100 & 100 & 100 \\
Rural $^{\mathrm{c}}$ & 41.2 & 56.0 & 68.8 & 51.4 \\
Urban $^{\mathrm{d}}$ & 18.5 & 10.0 & 18.8 & 39.2 \\
Migration $^{\mathrm{e}}$ & 40.3 & 33.9 & 12.4 & 9.4 \\
\hline
\end{tabular}

NoTES:

a. The decomposition relates to the terms of equation (2). National $=$ rural + urban + migration.

b. Mean annual value of $d P$, the year-on-year change in national poverty incidence.

c. Mean annual value of $\alpha^{R} d P^{R}$, the year-on-year population share-weighted change in rural poverty incidence.

d. Mean annual value of $\alpha^{U} d P^{U}$, the year-on-year population share-weighted change in urban poverty incidence.

e. Mean annual value of $\left(P^{R}-P^{U}\right) d \alpha^{R}$, the year-on-year migration-induced change in poverty incidence

SourCE: Author's calculations. 
Equation (2) states that the change in poverty incidence may be decomposed into three parts: (i) the change in rural poverty incidence, weighted by the rural population share, (ii) the change in urban poverty incidence weighted by the urban population share, and (iii) the movement of populations from rural to urban areas weighted by the difference in poverty incidence between these two areas.

The last of these terms is described by Anand and Kanbur (1985) as the "Kuznets effect". As the population moves from rural to urban areas, a change in aggregate poverty incidence will occur even at constant levels of rural and urban poverty incidence, provided that the levels of poverty incidence in these two sectors is different. In growing economies, we expect to find the rural population share falling $\left(d \alpha^{R}<0\right)$ and that the incidence of poverty in rural areas typically exceeds that in urban areas $\left(\left(P^{R}-P^{U}\right)>0\right)$. Thus, the expected sign of $\left(P^{R}-P^{U}\right) d \alpha^{R}$ is negative. How important the Kuznets effect is as a determinant of overall poverty reduction is, of course, an empirical matter.

First, we discuss the decomposition of the data on poverty incidence themselves. Table 8 shows the results of this decomposition. All results shown in this table are evaluated at the mean values of the data set. For example, the mean annual change in the aggregate level of poverty incidence for Indonesia was -1.414 percentage points per year (i.e., an annual reduction, on average, from numbers like 20 per cent to numbers like 18.586 per cent). Equation (2) above is an identity and must apply at all points in the data set. It must therefore apply at the means of the data. The equation shows that this mean aggregate change in poverty incidence can be decomposed into three components: average poverty reduction in urban areas, average poverty reduction in rural areas, and the movement of population between these two areas.

The second half of the table normalizes the decomposition by dividing all values by this mean change in aggregate poverty $(-1.862$ for Thailand, for example) and multiplying by 100 . For Thailand, reductions in rural poverty accounted for 56 per cent of the overall reduction in poverty, reduced urban poverty for 10 per cent and migration for 34 per cent.

For each of these four countries, poverty reduction in rural areas was the most important single contributor to the decline in poverty at the national level - accounting on average for a little over half of the poverty reduction that occurred. Nevertheless, rural to urban migration was also important in all four cases, especially Thailand and Indonesia, as was the reduction of poverty in urban areas. A lesson from these data is, therefore, that even though poverty incidence is indeed heavily concentrated in rural areas, poverty reduction over time is not just a matter of reducing poverty incidence in rural areas. Poverty can be, and is, reduced by attracting people away from rural areas to urban areas where economic conditions are more favourable and by reducing poverty in urban areas themselves.

The above calculations are, of course, merely descriptions of the data. We wish to know what caused these observed changes in poverty incidence and what caused the differences across countries. Poverty incidence and its changes over time obviously depends on many factors, of which economic variables are only part of the story and among the economic variables many issues aside from simply the overall rate of growth will be relevant. Nevertheless, the data suggest superficially that the overall rate of growth may be an important part of the story. The data on real GDP growth per person are summarized in Table 9, covering the same time periods as the poverty data reviewed above.

The growth of real GDP per person followed a pattern similar to these data on poverty incidence. The ranking of the four countries by annual rates of change of poverty incidence is (from fastest to slowest): Thailand, Malaysia, Indonesia, and the Philippines. The ranking by rates of real GDP growth per person is the same. At the level of individual economies, a relationship between the rate of poverty reduction over time and the rate of growth over time also seems possible. For example, in Thailand poverty incidence fell throughout the period indicated except for the 
TABLE 9

Annual Rates of Growth of Real GDP Per Person and Its Components

\begin{tabular}{lcccc}
\hline & Indonesia & Thailand & Malaysia & Philippines \\
\hline Total & 4.25 & 4.39 & 4.32 & 1.09 \\
Agriculture & 1.84 & 2.01 & 1.29 & 0.29 \\
Industry & 6.56 & 8.04 & 6.37 & 1.94 \\
Services & 4.17 & 5.33 & 4.96 & 1.64 \\
\hline
\end{tabular}

SourCE: World Bank, World Development Indicators, various issues.

recession period of the early 1980 s, when measured poverty incidence increased and again in the Asian crisis period of the late 1990s when it increased again. In all four cases the Asian financial crisis of 1997-98, which temporarily produced negative growth rates of real GDP per person, also temporarily reversed the long-term pattern of sustained poverty reduction. In the following section we examine this relationship between poverty reduction and economic growth more systematically.

\section{Analytical Framework}

\section{IV.1 Conceptual Framework}

We now turn to the manner in which poverty incidence is affected by economic growth. A central conceptual issue must be discussed first. Drawing a causal connection between economic growth and poverty reduction may seem strained because economic growth is not in itself a policy instrument, nor is it exogenous to the economic system. Economic growth is an outcome, determined by policy, external forces and the way market participants respond to them. Poverty reduction is similarly an outcome of the economic system. Drawing a causal connection between the two may thus appear to be an example of attempting to find stable relationships among endogenous variables of a causal system. In general, such relationships do not exist. The conceptual basis for relating poverty to economic growth is summarized in Figure 8.

The assumption being made is that one of the ways in which economic policies and other variables influence poverty is through their effects on output. That is, output is a conduit through which these variables act on poverty. They may affect it additionally through other channels as well, as indicated by the box "redistributional effects" in the figure, but these effects are assumed to be minor. We do not expect that all changes in poverty can be attributed to changes in output, but it is being assumed that one significant channel through which policy influences poverty is through its effect on output. This is the channel between policy and poverty that is studied by looking at the statistical relationship between poverty and growth.

In this framework, the possibility that changes in poverty incidence could have causal feedback effects on the rate of growth is explicitly excluded. Likewise, we exclude the possibility that the source of growth significantly influences its ultimate impact on poverty incidence. In this system, GDP and its sectoral components are (causally) an intermediate outcome of policy, as well as other factors, and poverty is a subsequent outcome. By studying the causal link between output (growth) and poverty, we are thus studying one component of the link between policy and external shocks, on one hand, and poverty incidence, on the other. 
FIGURE 8

Conceptual Framework: Growth and Poverty

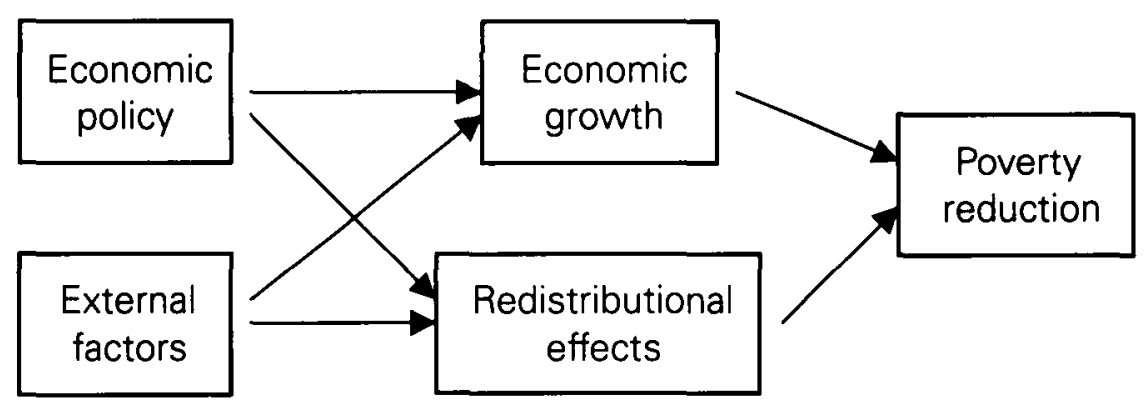

\section{IV.2 Data Pooling}

Indonesia, Thailand, Malaysia, and the Philippines were chosen for this study because all four data on poverty incidence are available over a period of at least two decades. However, the intervals between available data points are often several years long, which means that the total number of data points available for any one of these countries is still small. Statistical analysis of the relationship between poverty incidence and economic growth is highly problematic for any one of them, taken separately. But analysis of this kind becomes feasible when the data are appropriately pooled across countries.

There are reasons for thinking that pooling data for this particular group of four countries is reasonable. First, these counties have roughly similar economic structures. All four are marketoriented economies with agricultural sectors which consist primarily of small farming units and which dominate total employment, but not national output. In all four, industrial production has combined export-oriented production with protected production for domestic markets. All four have large services sectors which provide residual employment opportunities for those not employed in agriculture or industry. In all four, the rural populations dominate the total number of poor people, but rural to urban migration has been a prominent feature of the long-term development process. These facts suggest that the underlying relationship between sectoral growth and poverty reduction might be similar among these four countries, whereas this may not apply within groups of countries whose structural features differ widely.

Second, despite their structural similarities these countries have somewhat different economic histories. Except for the Philippines, all four experienced growth rates above their long-term historical norms during the boom decade from the mid-1980s to the mid-1990s, during which aggregate poverty incidence declined, followed by deep recessions from 1997 onwards, during which poverty incidence increased. But aside from this similarity their detailed experiences have been quite different. Thailand has grown most rapidly in all three sectors than the other three countries, and the Philippines the least rapidly. The rates at which agriculture has contracted as a share of GDP during the process of long-term economic growth have differed, along with rates of industrialization. The above facts suggest that these countries provide four different sets of empirical experience around a similar underlying structure, the circumstances in which pooling data is most likely to be appropriate. 


\section{IV.3 Poverty and Aggregate Growth}

For simplicity of exposition it is convenient to hypothesize initially that the total number of households in poverty, $N_{P}$, depends on the aggregate level of real income, $Y$, and the size of the population, $N$. The sectoral composition of the growth will be introduced later. We now turn to the manner in which poverty incidence is affected by economic growth and, for simplicity, we hypothesize initially that the total number of households in poverty, $N_{P}$, depends on the aggregate level of real income, $Y$, and the size of the population, $N$. Thus

$$
N_{P}=\varphi(Y, N) \text {. }
$$

National poverty incidence is now

$$
P=N_{P} / N=\varphi(Y, N) / N .
$$

Totally differentiating this equation,

$$
d P=\left(\varphi_{Y} Y / N\right) y+\left(\varphi_{N}-\varphi / N\right) n,
$$

where lower case Roman letters represent the proportional changes of variables represented in levels by upper case Roman letters. Thus $y=d Y / Y$ and $n=d N / N$ are the growth rates of aggregate real income and of population, respectively. In the special case where the function $\varphi($.$) is homogeneous of degree one in$ $Y$ and $N$, (3) may be written $N_{P}=\varphi_{Y} Y+\varphi_{N} N$ and (5) reduces to

$$
d P=\left(\varphi_{Y} Y / N\right)(y-n) .
$$

In this case the change in poverty incidence depends on the growth of per capita income. If this assumption is not imposed, then we can estimate relationships of the kind

$$
d P=a^{1}+b^{1} y+c^{1} n
$$

and test whether the coefficient $b^{1}$ is significantly greater than zero. We could also test whether $b^{1}=-c^{1}$, that is, whether the growth of per capita income is the determinant of the change in poverty incidence, as in (6), or whether population growth affects the reduction in poverty incidence in some other way.

We wish to study the way economic growth affects each of the components of the change in aggregate poverty incidence, as given by equation (2) above. Ravallion and Datt apply an ingenious method for estimating decomposed equations systems of this kind. We have a four-equation system, consisting of (7) and:

$$
\begin{aligned}
\alpha^{R} d P^{R} & =a^{2}+b^{2} y+c^{2} n \\
\alpha^{U} d P^{U} & =a^{3}+b^{3} y+c^{3} n \\
\left(P^{R}-P^{U}\right) d \alpha^{R} & =a^{4}+b^{4} y+c^{4} n .
\end{aligned}
$$

But from the identity given by (2), these equations are linearly dependent. Equation (7) is identically the sum of equations (8), (9), and (10). Of these four equations, only three need to be estimated. The parameters of the fourth can be computed from (2) and the other three, using the identities $a^{4}=a^{1}-a^{2}-a^{3}, b^{4}=b^{1}-b^{2}-b^{3}$, and $c^{4}=c^{1}-c^{2}-c^{3}$.

\section{IV.4 Poverty and Sectoral Growth}

Whether the sectoral composition of economic growth affects poverty reduction can now be investigated as follows. The level of real GDP is given by $Y=Y_{a}+Y_{i}+Y_{s}$, where $Y_{a}, Y_{i}$, and $Y_{s}$ denote value-added (contribution to GDP) at constant prices in agriculture, industry, and services, respectively. The overall rate of growth can be decomposed into its sectoral components from

$$
y=H_{a} y_{a}+H_{i} y_{i}+H_{s} y_{s},
$$

where $H_{k}=Y_{k} / Y, k=(a, i, s)$, denotes the share of sector $k$ in GDP. The effect of sectoral growth can now be studied by substituting (11) into equations (7), (8), and (9). By estimating the equation

$$
d P=a^{1}+b_{a}^{1} H_{a} y_{a}+b_{i}^{1} H_{i} y_{i}+b_{s}^{1} H_{s} y_{s}+c^{1} n
$$


and testing whether $b_{a}^{\prime}=b_{i}^{\prime}=b_{s}^{\prime}$, we may test directly whether the sectoral composition of growth affects the rate of poverty reduction.

An alternative way of viewing this relationship is to decompose equation (12) into a component depending on the aggregate rate of growth and a component depending on changes in its composition. Noting that $Y_{a}=\left(Y_{a} / Y\right) Y=H_{a} Y$,

$$
y_{a}=y+h_{a}
$$

where $h_{a}=d H_{a} / H_{a}$ denotes the proportional change in agriculture's sectoral share of GDP. It follows that

$$
\begin{aligned}
& b_{a}^{1} H_{a} y_{a}+b_{i}^{1} H_{i} y_{i}+b_{s}^{1} H_{s} y_{s} \\
&=\left(b_{a}^{1} H_{a}+b_{i}^{1} H_{i}+b_{s}^{1} H_{s}\right) y+b_{a}^{1} H_{a} h_{a} \\
&+b_{i}^{1} H_{i} h_{i}+b_{s}^{1} H_{s} h_{s} .
\end{aligned}
$$

The impact of sectoral growth can thus be broken into two parts: one involving the aggregate rate of growth (with the coefficient in parentheses), and a second involving changes in its composition (the final three terms). Clearly, this expression reduces to a term in $y$ alone if and only if the final three terms sum to zero. Now, by differentiating the identity $H_{a}+H_{i}+H_{s}=1$, we see that

$$
H_{a} h_{a}+H_{i} h_{i}+H_{s} h_{s}=0
$$

Therefore, a sufficient condition for the final three terms of (14) to vanish is that $b_{1}=b_{2}=b_{3}$, as discussed in relation to equation (12) above. It follows that to apply this decomposition, no additional econometrics is necessary beyond the estimation of equations like (12). Estimation of the parameters of (12) is sufficient to support the decomposition represented by (14).

Applying the method of equations (7), (8), and (9) above, we estimate the system

$$
\begin{aligned}
d P= & a^{1}+b_{a}^{1} H_{a} y_{a}+b_{i}^{1} H_{i} y_{i}+ \\
& b_{s}^{1} H_{s} y_{s}+c^{1} n
\end{aligned}
$$

$$
\begin{aligned}
\alpha^{R} d P^{k}= & a^{2}+b_{a}^{2} H_{a} y_{a}+b_{i}^{2} H_{i} y_{i}+ \\
& b_{s}^{2} H_{s} y_{s}+c^{2} n \\
\alpha^{\nu} d P^{U}= & a^{3}+b_{a}^{3} H_{a} y_{a}+b_{i}^{3} H_{i} y_{i}+ \\
& b_{s}^{3} H_{s} y_{s}+c^{3} n
\end{aligned}
$$

The parameters of the fourth equation of the system

$$
\begin{aligned}
\left(P^{R}-P^{U}\right) d \alpha^{R}= & a^{4}+b_{a}^{4} H_{a} y_{a}+b_{i}^{4} H_{i} y_{i}+ \\
& b_{s}^{4} H_{s} y_{s}+c^{4} n
\end{aligned}
$$

are then computed using identities derived from (2), as before: $a^{4}=a^{1}-a^{2}-a^{3}, b_{a}^{4}=b_{a}^{1}-b_{a}^{2}-b_{a}^{3}$ and so forth.

\section{Results}

The regression results are summarized in Table 10. As noted above, data are pooled for Indonesia, Thailand, Malaysia, and the Philippines. The method of pooling requires explanation. Considering the differences between these countries in the measurement of poverty, the real value of the poverty lines, the position and shape of the cumulative income distribution and the detailed structure of the four economies, it could hardly be expected that the same numerical relationship between poverty incidence and economic growth could be obtained in all four countries.

The method used here employs dummy intercept variables to capture these differences. Dummy variables are used for three of the four countries. Their coefficients amend the intercept coefficients estimated for the fourth country. The results are the same whichever country is selected as the "fourth". It is, of course, being assumed in this pooling process that the slope coefficients are the same for all four Southeast Asian countries.

If sectoral economic growth and population growth affected poverty reduction jointly through their effects on per capita sectoral growth, equation (16) could be rewritten as: 


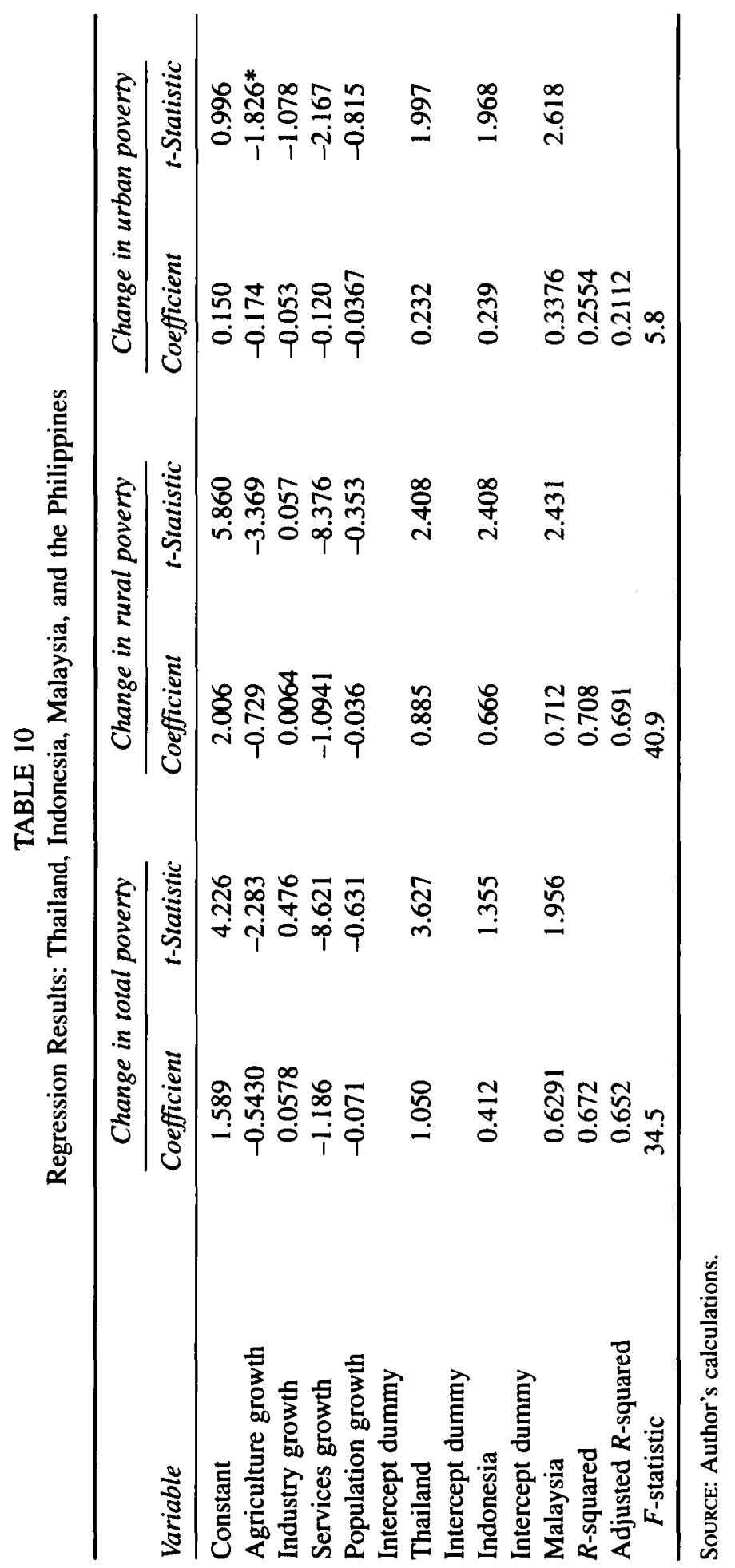




$$
\begin{aligned}
d P= & a^{1}+b_{a}^{1} H_{a}\left(y_{a}-n\right)+b_{i}^{1} H_{i}\left(y_{i}-n\right)+ \\
& b_{s}^{1} H_{s}\left(y_{s}-n\right),
\end{aligned}
$$

and similarly for equations (17) to (19). That is, (16) to (19) would each satisfy the restriction that $b_{a}^{j} H_{a}+b_{i}^{j} H_{i}+b_{s}^{j} H_{s}=c^{j}, j=(1 \ldots ., 4)$. When this restriction was imposed on the estimates of equations (16) to (18) it was rejected at the 95 per cent level of significance. We shall therefore not impose this assumption. Population growth is therefore treated as a separate variable, as in equations (16) to (19). It is convenient to focus the discussion on the equation for aggregate poverty incidence, equation (16).

The estimated coefficients for agriculture and services were negative and significantly different from zero at the 95 per cent confidence level. Growth of agriculture and services was thus strongly associated with reductions in poverty. The coefficient for industry was not significantly different from zero. The null hypothesis that the three coefficients were the same was rejected by an $F$-test at the 95 per cent level.

According to these results, the growth of output in the agricultural and services sectors is consistently associated with poverty reduction. The difference arises with industrial growth. Industry growth was neutral with respect to poverty incidence. Qualitatively similar results are obtained for the equation on rural poverty reduction, also shown in Table 10.

It is convenient now to compare these results with earlier but similar studies for two Asian economies for which data were sufficient to enable this statistical approach to be followed for a single economy. These are Taiwan (Warr and Wang (1999); and India (Warr 2005). ${ }^{3}$ In both these cases growth of agricultural and services output was associated with reduced poverty, as in the Southeast Asian case. The differences arise with industrial growth. In Taiwan, growth of industry was strongly associated with poverty reduction. In India (1957 to 1997) it was associated with rising poverty. The results for Southeast Asia are exactly intermediate. An obvious explanation is available.
The trade policy regimes under which the industrial growth occurred were radically different in these three case studies.

In Taiwan, growth of industry was not based on import-substitution policies. Industry received little protection; agriculture was the more highly protected sector. The result was a pattern of industrialization that was relatively labourintensive, contained a substantial small enterprise component and was closely linked to rural areas. In India heavy protection of industry led to a capital intensive, large-scale and urban-based pattern of industrialization (Srinivasan 2000 and Jha 2003). Southeast Asian industrial policies were exactly intermediate between these two extremes. They were not as protectionist as India's, not as liberal as Taiwan's. The effects on poverty reduction were similarly intermediate. But why?

The Stolper-Samuelson theorem (Lloyd 2000) leads us to expect that a capital-intensive industrial strategy will reduce real wages by reducing the demand for labour and increase the return to capital. It is well understood that a strongly protectionist trade policy will reduce the rate of growth. The above results suggest that, in addition, it will promote a pattern of industrial growth that does not serve the objective of reducing poverty.

Returning to Table 10 and the results for Southeast Asia, the results can be analysed further by decomposing the respective contributions that growth in agriculture, industry and services have made to the mean rate of poverty reduction that was achieved. These decompositions exploit the fact that the estimated regression equations must pass through the means of the data. Therefore, if we substitute the mean values of the data into the estimated equation, the left and right hand sides will be exactly equal.

We shall estimate the historical contributions that growth in each sector has made to the achieved rates of poverty reduction shown in Tables 1 to 4 . These estimated effects will depend on three matters, each evaluated at the means of the data: (a) the marginal effect of a 1 per cent contribution to GDP growth originating from each 
sector; (b) the growth rates of net output (valueadded) actually achieved in each sector; and (c) the mean sectoral shares of GDP originating in each sector (ratio of sectoral value-added to aggregate GDP). The product of (b) and (c) is, of course, the contribution that output growth in a particular sector has made to GDP growth. The sum of these products across sectors must be equal to the rate of GDP growth actually achieved, as indicated by equation (14), above.

The results are shown in Tables 11A to 11D. It is striking that although industry contributed between 39 and 48 per cent of GDP growth in these four countries, growth of industry did not contribute to poverty reduction at all, for the reasons discussed above. Second, growth of services output was more important than growth of agriculture for the reduction in aggregate poverty that actually occurred in all countries except Indonesia, where agricultural output has grown rapidly and this sector remains a relatively high share of GDP.

Finally, Tables $12 \mathrm{~A}$ to $12 \mathrm{D}$ decompose the reductions in poverty incidence which occurred into two components: a "growth effect" - the reduction in poverty that would have occurred if all sectors had grown at the rate of growth of GDP; and a "compositional effect" - the reduction in poverty that resulted from deviations from uniform sectoral growth rates. These decompositions exploit the analytical result derived in equation (18) above, which separates

TABLE 11A

Indonesia: Poverty Reduction and Sectoral Growth - Decomposition

(Mean percentage change per year, normalized to national $=100$ )

\begin{tabular}{lccccc}
\hline \multirow{2}{*}{$\begin{array}{l}\text { Poverty } \\
\text { reduction }\end{array}$} & Actual & Constant & Agriculture & Industry & Services \\
\cline { 3 - 6 } & 100 & -160 & 180 & -41 & 121 \\
National & 41 & -234 & 138 & -37 & 174 \\
Rural & 19 & -58 & 50 & 38 & -10 \\
Urban & 40 & 134 & -8 & -42 & -44 \\
Migration & &
\end{tabular}

SourCE: Author's calculations.

TABLE 11B

Thailand: Poverty Reduction and Sectoral Growth - Decomposition

(Mean percentage change per year, normalized to national $=100$ )

\begin{tabular}{lccccc}
\hline \multirow{2}{*}{$\begin{array}{l}\text { Poverty } \\
\text { reduction }\end{array}$} & Actual & Constant & Agriculture & Industry & Services \\
\cline { 3 - 6 } & 100 & -153 & 109 & -14 & 159 \\
National & 56 & -140 & 94 & -19 & 139 \\
Rural & 10 & -41 & 34 & 34 & -1 \\
Urban & 34 & 33 & -18 & -29 & 21 \\
Migration & 34 & & & &
\end{tabular}

SOURCE: Author's calculations. 
TABLE 11C

Malaysia: Poverty Reduction and Sectoral Growth - Decomposition

(Mean percentage change per year, normalized to national $=100$ )

\begin{tabular}{lccccc}
\hline \multirow{2}{*}{$\begin{array}{l}\text { Poverty } \\
\text { reduction }\end{array}$} & Actual & Constant & Agriculture & Industry & Services \\
\cline { 3 - 6 } & 100 & -5 & 15 & -1 & 91 \\
National & 69 & 58 & 37 & 6 & -32 \\
Rural & 19 & -62 & 21 & 44 & 17 \\
Urban & 12 & -2 & -43 & -50 & 106 \\
Migration & 12 & &
\end{tabular}

SourCE: Author's calculations.

TABLE $11 \mathrm{D}$

Philippines: Poverty Reduction and Sectoral Growth - Decomposition

(Mean percentage change per year, normalized to national $=100$ )

\begin{tabular}{lccccc}
\hline \multirow{2}{*}{$\begin{array}{l}\text { Poverty } \\
\text { reduction }\end{array}$} & Actual & Constant & Agriculture & Industry & Services \\
\cline { 3 - 6 } National & 100 & 79 & 1 & -68 & 87 \\
Rural & 51 & 115 & 41 & -7 & -97 \\
Urban & 39 & 15 & 5 & 57 & 15 \\
Migration & 9 & -51 & -3 & -118 & 169 \\
\hline
\end{tabular}

SourcE: Author's calculations.

TABLE $12 \mathrm{~A}$

Indonesia: Poverty Reduction and Sectoral Growth - Decomposition

(Mean percentage change per year, normalized to national $=100$ )

\begin{tabular}{lcccc}
\hline Poverty & & \multicolumn{3}{c}{ Estimated } \\
\cline { 3 - 5 } reduction & Actual & Constant & Growth & Composition \\
\hline National & 100 & -160 & 411 & -151 \\
Rural & 41 & -234 & 377 & -102 \\
Urban & 19 & -58 & 128 & -50 \\
Migration & 40 & 134 & -94 & 1 \\
\hline
\end{tabular}

Source: Author's calculations. 
TABLE 12B

Thailand: Poverty Reduction and Sectoral Growth - Decomposition (Mean percentage change per year, normalized to national $=100$ )

\begin{tabular}{lcccc}
\hline \multirow{2}{*}{$\begin{array}{l}\text { Poverty } \\
\text { reduction }\end{array}$} & Actual & Constant & Growth & Composition \\
\cline { 3 - 5 } & 100 & -153 & 346 & -93 \\
National & 56 & -140 & 299 & -85 \\
Rural & 10 & -41 & 109 & -43 \\
Urban & 34 & 33 & -61 & 35 \\
Migration & & & &
\end{tabular}

SourcE: Author's calculations.

TABLE $12 \mathrm{C}$

Malaysia: Poverty Reduction and Sectoral Growth - Decomposition (Mean percentage change per year, normalized to national $=100$ )

\begin{tabular}{lcccc}
\hline \multirow{2}{*}{$\begin{array}{l}\text { Poverty } \\
\text { reduction }\end{array}$} & Actual & Constant & Growth & Composition \\
\cline { 3 - 5 } National & 100 & -5 & 114 & -9 \\
Rural & 69 & 58 & 39 & -29 \\
Urban & 19 & -62 & 91 & -11 \\
Migration & 12 & -2 & -16 & 30 \\
\hline
\end{tabular}

SourCE: Author's calculations.

TABLE 12D

Philippines: Poverty Reduction and Sectoral

Growth - Decomposition

(Mean percentage change per year, normalized to national $=100$ )

\begin{tabular}{lcccc}
\hline \multirow{2}{*}{$\begin{array}{l}\text { Poverty } \\
\text { reduction }\end{array}$} & Actual & Constant & Growth & Composition \\
\cline { 2 - 5 } National & 100 & 79 & 16 & 5 \\
Rural & 51 & 115 & -46 & -18 \\
Urban & 39 & 15 & -4 & 29 \\
Migration & 9 & -51 & 65 & -6 \\
\hline
\end{tabular}

SourCE: Author's calculations. 
the effect of sectoral growth into two components: one depending on the aggregate growth rate and a second depending on the changing composition of GDP. The results may be somewhat surprising. In all four countries, the growth effect dominates. The changing composition of GDP has been much less important for explaining the reduction of poverty incidence than the aggregate rate of GDP growth. According to these results, the changing sectoral composition of growth has affected the rate at which poverty incidence has declined in Southeast Asia, but the aggregate rate of growth has been far more important.

Two final observations from Table 10 are important. First, the independent variables used in this analysis together explain about two thirds of the variation in poverty reduction that occur in the sample. Growth and its composition are important for explaining poverty reduction, but they are far from being the full story. Second, the omitted determinants of changes in poverty are in this analysis collapsed into the constant term. Tables $11 \mathrm{~A}$ to $11 \mathrm{D}$ and $12 \mathrm{~A}$ to $12 \mathrm{D}$ show that the constant terms are large and important, confirming again that attempting to explain changes in poverty solely through economic growth is insufficient.

\section{Conclusions}

The seven Southeast Asian countries studied in this paper - Thailand, Indonesia, Malaysia, the Philippines, Cambodia, Lao PDR, and Vietnam have each achieved significant reductions in poverty incidence in recent decades. According to statistical analysis covering the first four of these countries, the achievement of poverty reduction was mainly attributable to the aggregate rate of growth; changes in the sectoral composition of the growth had much less impact. The results confirm that the poverty reduction outcome was strongly related to growth of agriculture and services, but not to the growth of industry. In three of the four countries (Indonesia is the exception) growth of services made a larger net contribution to poverty reduction than growth of agriculture because the contribution that services growth has made to overall economic growth has been much larger.

The importance of agricultural development for poverty reduction is widely understood but the contribution of the services sector is larger, and its role has been much less widely appreciated. More surprisingly, our results indicate that the growth of industry has not contributed to poverty reduction in Southeast Asia.

The principal income source of poor people is their own labour - largely unskilled. Agricultural land is also an important asset, but much less so. Development which increases the demand for these two resources raises the incomes of poor people and consequently reduces poverty incidence. This presumably explains the differences in the povertyreducing power of growth in different sectors of the economy which have been analysed in this paper. In the four Southeast Asian countries studied here, considered as a group, growth of the agricultural and services sectors have each reduced poverty considerably. Growth of the industrial sector has not. The results support the hypothesis that an import-substitution based industry policy promotes a pattern of industrialization which does not advance the welfare of poor people because it contributes insufficiently to expanding the demand for the principal resource which they own unskilled labour.

The analysis contained in this paper, and others which also relate poverty reduction outcomes directly to rates of economic growth, rests on a strong assumption. It assumes that the source of the growth (aggregate or sectoral) - whether it derives from accumulation of physical capital, human capital, or improvements in factor productivity resulting from technological change - does not affect the poverty-reducing power of the growth. This assumption may or may not be correct. Future research may illuminate this issue further. 


\section{NOTES}

Excellent research assistance from Arief Ramayandi is gratefully acknowledged. The paper also benefited from kind assistance with data from Arsenio Balisacan, Asep Suryahadi, and Rogayah Haji Mat Zin. The author accepts responsibility for all defects.

1. This lack of consensus often derives from a failure to distinguish properly between the concepts of absolute poverty and relative inequality.

2. In 1999 a special round of the SES was conducted to provide more information on the impact of the economic crisis. This special round of the SES has since been repeated in odd-numbered years (2001 and 2003) but the sample size is much smaller than that used in the usual SES survey conducted in even-numbered years and the results are considered less reliable.

3. See also Ravallion and Datt (1996) for an earlier study of this kind for India. Warr (2005) extends the data set used by Ravallion and Datt (1996) and also develops the econometric methodology further.

\section{REFERENCES}

Anand, Sudhir and S. M. R. Kanbur. "Poverty Under the Kuznets Process". Economic Journal 95 (1985): 42-50.

Balisacan, Arsenio. "Poverty and Inequality". In The Philippine Economy: Development, Policies and Challenges, edited by Arsenio Balisacan and Hal Hill, pp. 311-41. Oxford: Oxford University Press, 2002.

Chenery, Hollis B. and Moshe Syrquin. "Typical Patterns of Transformation". In Industrialization and Growth, edited by Hollis B. Chenery, Sherman Robinson and Moshe Syrquin. New York: Oxford University Press, 1986.

Fields, Gary S. Poverty, Inequality and Development. Cambridge: Cambridge University Press, 1980.

Islam, Iyanatul. "Why Inequality Matters: A Contribution to the Indonesian Development Agenda". United Nations Support Facility for Indonesian Recovery. Discussion Paper Series No. 04/08, August 2004.

Jha, Raghabendra, ed. Indian Economic Reforms. Houndmills, Basingstoke: Macmillan, 2003.

Krongkaew, Medhi. "Income Distribution and Poverty". In The Thai Economy in Transition, edited by Peter Warr. Cambridge: Cambridge University Press, 1993.

Lloyd, Peter. "Generalizing the Stolper-Samuelson Theorem: A Tale of Two Matrices". Review of International Economics, 8 (2000): 597-613.

Ravallion, Martin, and Gaurav Datt. "How Important to India's Poor Is the Sectoral Composition of Economic Growth?". World Bank Economic Review 10 (1996): 1-25.

Rogayah Haji Mat Zin. "Inequality, Poverty and Social Safety Nets: The Malaysian Experience". Unpublished paper, 2004.

Srinivasan, T. N. Eight Lectures on India's Economic Reforms. New Delhi: Oxford University Press, 2000.

Warr, Peter. "Globalization, Growth and Poverty Reduction in Thailand". ASEAN Economic Bulletin 21, no. 1 (2004): 1-18.

. "Poverty, Inequality and Economic Growth: India 1957 to 1997". In Economic Growth, Economic Performance and Welfare in South Asia, edited by Raghabendra Jha, pp. 343-68. Basingstoke, Hampshire: Palgrave Macmillan, 2005.

Warr, Peter G. and Wang Wen-thuen. "Poverty, Inequality and Economic Growth in Taiwan". In The Political Economy of Development in Taiwan: Essays in Memory of John C. H. Fei, edited by Gustav Ranis and Hu Sheng-cheng, pp. 133-65. London: Edward Elgar, 1999.

World Bank. East Asia Rebounds, But How Far? Washington, D.C.: World Bank, 2002.

Peter Warr is John Crawford Professor of Agricultural Economics and Director, Poverty Research Centre, Division of Economics, Research School of Pacific and Asian Studies, The Australian National University, Canberra, Australia. 